\title{
A New Approach towards Improving the Specific Energy and Specific Power of a Carbon-Based Supercapacitor using Platinum-Nanoparticles on Etched Stainless Steel Current Collector
}

\section{Rakhmawati FARMA, ${ }^{a}$ Mohamad DERAMAN, ${ }^{b, *}$ Sepideh SOLTANINEJAD, ${ }^{c}$ AWITDRUS, ${ }^{a}$

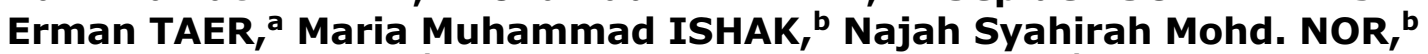 Nur Hamizah BASRI, b Besek Nurdiana Mohd. DOLAH, ${ }^{b}$ Norinsan Kamil OTHMAN, ${ }^{b}$ Mohd. Amir Radhi OTHMAN, ${ }^{b}$ Rusli DAIK, ${ }^{c}$ Mohd SULEMAN, ${ }^{b}$ and Gurumurthy HEGDEd}

\author{
a Department of Physics, University of Riau, 28293 Simpang Baru, Riau, Indonesia \\ b School of Applied Physics, Faculty of Science and Technology, Universiti Kebangsaan Malaysia, \\ 43600 Bangi, Selangor, Malaysia \\ c School of Chemical Science and Food Technology, Faculty of Science and Technology, \\ University Kebangsaan Malaysia, 43600 Bangi, Selangor, Malaysia \\ d BMS R and D Centre, BMS College of Engineering, Basavanagudi, 560019 Bangalore, India \\ *Corresponding authors: madra@ukm.edu.my; mderaman113@gmail.com
}

\begin{abstract}
We report an improved performance of a carbon-based supercapacitor using etched stainless steel (SS) current collector deposited with platinum nanoparticles (PtNs) over bare SS current collector/un-etched SS current collector deposited with PtNs. The PtNs grown on the etched surface of the current collectors provides a better contact with the surface of activated carbon monoliths electrode prepared from pre-carbonized fibres of oil palm empty fruit bunches. X-ray diffraction, field-emission scanning electron microscopy, the energy dispersive X-ray analysis, and X-ray photoelectron spectroscopy were employed to investigate the different properties of bare SS current collector and the modified current collector. Electrochemical impedance spectroscopy, cyclic voltammetry and galvanostatic charge-discharge results consistently suggest that the deposition of PtNs on the etched surface of the current collector causes an increase in specific capacitance of $10 \%$ (from 105 to $115 \mathrm{Fg}^{-1}$ ), $4 \%$ (from 141 to $146 \mathrm{~F} \mathrm{~g}^{-1}$ ) and $6 \%$ (from 142 to $150 \mathrm{Fg}^{-1}$ ) respectively. Correspondingly, the specific energy increases from 4.12 to $4.51 \mathrm{Wh} \mathrm{kg}^{-1}$ and specific power from 173 to $196 \mathrm{~W} \mathrm{~kg}^{-1}$. Also EIS and GCD results respectively show a decrease of $47 \%$ (from 1.332 to $0.710 \Omega$ ) and $44 \%$ (from 1.75 to $0.974 \Omega$ ) in equivalent series resistance.
\end{abstract}

(c) The Electrochemical Society of Japan, All rights reserved.

Keywords : Supercapacitor Performance, Platinum Nanoparticles, Activated Carbon Electrodes, Current Collector

\section{Introduction}

Among various energy storage/conversion devices such as rechargeable batteries or fuel cells, supercapacitors or electrochemical capacitors or ultracapacitors are the most promising energy storage devices which offer higher specific energy than conventional capacitors and higher power density and longer cycling life than rechargeable batteries. ${ }^{1-3}$ According to the types of electrode materials and charge storage mechanism there are two classes of supercapacitors namely electrical double-layer capacitors (EDLCs) which employ variety of carbon-based materials (activated carbon like carbon powders/fibers/monoliths/tubes, carbon nanotubes, graphene, etc.) as electrode and the redox capacitors or pseudocapacitors which use metal oxides (manganese oxide, ruthenium oxide, nickel oxide, etc.) or conducting polymers (polyaniline, polypyrrole, etc.) as electrodes. ${ }^{4}$ In EDLCs, the capacitance comes from fast electrostatic charge accumulation via reversible ion absorption at the electrode/electrolyte interface (non-faradaic process) which leads to rapid power delivery and longer cycling life as compared to pseudocapacitors where the capacitance is caused by fast and reversible redox reactions (faradaic processes) occurring at the surface of electroactive materials. ${ }^{4}$ The major components of the supercapacitors, namely the electrodes, electrolytes, separator, current collectors, etc., play a significant role to determine the performance of supercapacitors. ${ }^{4,5}$ Therefore, there have been a lot of efforts to improve these components in order to achieve enhanced specific energy and power densities of supercapacitors. ${ }^{6-8}$ Despite the fact that both the power and energy storage densities are critically important for supercapacitor performance, there have been sparse literature reports on the study to increase the power storage density of the supercapacitors. It is well known that the maximum power density of a supercapacitor is given by equation:

$$
P_{\max }=V / 4 R
$$

where $V$ is the operating voltage, determined by the electrochemical stability window of the electrolyte and $R$, is the equivalent series resistance (ESR). ${ }^{9-11}$ The ESR, is a collective measure of all kinds of resistances contributed by various sources present in the supercapacitors that include the resistance of current collector; the interfacial resistance between the electrode material and the currentcollector; electronic resistance of the electrode material; the ionic (diffusion) resistance of ions transporting through smaller pores; the ionic resistance of ions moving through the separator; and the electrolyte resistance. ${ }^{9-11}$ The power density of the supercapacitor can therefore be increased either by increasing the potential or by reducing the ESR. Higher potential can be controlled by modifying the electrolyte properties, ${ }^{12,13}$ while a lower ESR value can be achieved by reducing the internal resistance of the electrode and the contact resistance between the electrodes and the current collectors. ${ }^{9}$ It has been observed that supercapacitors with low ESR values can be fabricated by modifying aluminium current collectors with carbon material via sol-gel and coating, ${ }^{11}$ modifying aluminium current 
collectors with carbon and carbon electrodes modified with carbon nanotubes, ${ }^{14,15}$ modifying carbon electrodes using monolith forms. ${ }^{15-26}$ Studies on the modification of separators have also been reported elsewhere. ${ }^{27,28}$ Recently, the low ESR value has been achieved by modifying the SS current collector by the deposition of platinum nanoparticles, wherein the modified current collector was tested in supercapacitor cell fabricated with activated carbon monolith (ACM) electrode derived from rubber wood saw dust. ${ }^{29}$

In the present study, an approach to reduce the ESR values of a supercapacitor cell is carried out by modifying the surface of the SS current collector (316L), viz by growing platinum nanoparticles $(\mathrm{PtNs})$ on its etched surface and then getting this modified surface in contact with the monolithic form of carbon electrodes which was prepared from pre-carbonized fibres of oil palm empty fruit bunches (OPEFB). ${ }^{20-23,29}$ The role of etching prior to PtNs deposition on the current collector surface was found to be very significant in enhancing the power and energy of the supercapacitor cells.

\section{Experimental}

\subsection{Electrode preparation, growth of platinum nanoparticles and cell fabrication}

OPEFB used in this study have been previously exploited for producing binderless carbon monoliths. ${ }^{30-32}$ ACMs were prepared from OPEFB according to the procedure mentioned in our previous work. ${ }^{20,29}$ The preparation began with the pre-carbonization of fibres of OPEFB at a low carbonization temperature $\left(280^{\circ} \mathrm{C}\right)$, followed by a ball milling for $36 \mathrm{~h}$ and finally sieving to obtain a powder of selfadhesive carbon grains (SACGs) having a particle size of less than $106 \mu \mathrm{m}$. The SACGs were converted into green monoliths (GMs) using a mold (20 mm in diameter) and $250 \mathrm{~kg} \mathrm{~cm}^{-2}$ of compressive force before they were carbonized at $800^{\circ} \mathrm{C}$ under $\mathrm{N}_{2}$ atmosphere with a heating profile used in our previous study to produce carbon monoliths $(\mathrm{CMs}){ }^{21}$ The $\mathrm{CMs}$ from the GMs were activated by a $\mathrm{CO}_{2}$ activation process at a temperature of about $800^{\circ} \mathrm{C}$ (heating rate of $5^{\circ} \mathrm{C}$ per min) for an activation time of $\sim 3 \mathrm{~h}$ to produce ACMs, following the procedure mentioned in our work reported previously. ${ }^{21}$ The ACMs were polished to the desired thickness $(\simeq 0.4$ $0.5 \mathrm{~mm}$ ) and then washed with a copious amount of distilled water and dried until $\mathrm{PH} \sim 7$ was achieved.

A platinum nanoparticle solution was prepared by mixing $1 \mathrm{~mL}$ of $0.01 \mathrm{M}$ solution of $\mathrm{K}_{2} \mathrm{PtCl}_{4}$ in $20 \mathrm{~mL}$ of deionized (DI) water. Thereafter this solution was mixed with $1 \mathrm{~mL}$ of a $0.2 \mathrm{M}$ solution of ascorbic acid $\left(\mathrm{C}_{6} \mathrm{H}_{8} \mathrm{O}_{6}\right){ }^{22,29,33}$ Prior to the deposition of platinum nanoparticles on the surface of the SS current collector, the SS was washed using acetone and ethanol for 10 min using an ultrasonic bath, respectively. The SS was soaked in the nanoparticle growth solution for $4 \mathrm{~h}$, after that the samples were removed, rinsed with DI water, dried and then soaked again in the new growth solution for the next $4 \mathrm{~h}$. This step was repeated 3 times. Finally, the SS-PtNs was removed from the solution, followed by rinsing and drying. To etch the surface of current collector, the SS was placed in $\mathrm{H}_{2} \mathrm{SO}_{4}$ $(2.5 \mathrm{M})$ and $\mathrm{HCl}(0.5 \mathrm{M})$ acid solutions in a beaker for $4 \mathrm{~h}$. The etched SS surface was then grown with platinum nanoparticles using the above procedure.

The symmetrical supercapacitor cells were fabricated and labelled as ACM0, ACM1 and ACM2 which respectively use the bare SS current collector (SS0), SS current collector with nanoplatinum (SS1), and etched SS current collector with nanoplatinum (SS2). Each cell was comprised of two ACM electrodes, two current collectors and a Teflon ring spacer between the two electrodes to create a space for $1 \mathrm{M}$ solution of the $\mathrm{H}_{2} \mathrm{SO}_{4}$ electrolyte. The thicknesses of the current collectors and Teflon ring spacer were $0.06 \mathrm{~mm}$ and $0.2 \mathrm{~mm}$ respectively. The diameter, thickness and weight of the ACMs were standardised to $15 \mathrm{~mm}, 0.4-0.5 \mathrm{~mm}$ and 40-50 mg, respectively.

\subsection{Physical properties}

The structures of the current collectors, SS0, SS1 and SS2 were investigated using X-ray diffraction (XRD). The diffraction patterns were obtained using a diffractometer (Bruker AXS D8 advance) that employed $\mathrm{Cu}-\mathrm{K}_{\alpha}$ radiation with the $2 \theta$ range from $0^{\circ}$ to $60^{\circ}$. The morphology and elemental composition of the bare SS current collector and that of modified SS current collectors were determined using the field-emission scanning electron microscope (FESEM) and the energy dispersive X-ray analysis (EDAX) instruments (Supra PV 55), respectively. X-ray photoelectron spectroscopy (XPS) technique was used to record the spectra of photoelectron intensity against binding energy for the sample SS0, SS1 and SS2 over an energy range of 0 to $1400 \mathrm{eV}$. The instrument used was a spectrometer (model Axis Ultra DLD, KratosUK) which employed an X-ray source emitting Al- $\mathrm{K}_{\alpha}$ radiation at $1486.6 \mathrm{eV}$. During the measurement, the pressure in the analysing chamber was kept with a minimum value of $5 \times 10^{-9}$ Torr.

The porosity parameters of the ACMs, such as BrunauerEmmett-Teller (BET) surface area, micropore surface area, total pore volume and average pore diameter, were determined from nitrogen adsorption-desorption isotherm data recorded at $-196^{\circ} \mathrm{C}$ using an accelerated surface area and porosimeter system (ASAP 2010 Micromeritics). The BET surface area was estimated from the isotherms data using the BET equation. This experiment assumed that the cross-sectional area of a nitrogen molecule was $\sim 0.162 \mathrm{~nm}^{2}$. The Dubinin-Radushkevich equation was used to calculate the micropore volume from the isotherms data. This calculated micropore volume value was used to determine the micropore surface area. The total pore volume was determined from the liquid volume of the adsorbate $\left(\mathrm{N}_{2}\right)$ at a relative pressure of 0.995 Torr.

\subsection{Electrochemical properties}

The electrochemical investigation of the fabricated supercapacitor cells was carried out by galvanostatic charge-discharge (GCD), electrochemical impedance spectroscopy (EIS) and cyclic voltammetry (CV) methods using a Solatron 1286 Electrochemical work station equipped with a Z-view software programming for the data analysis. The specific capacitance was determined using equation:

$$
C_{\mathrm{sp}}=2 C / m
$$

where, $C$ is the capacitance of the cells and $m$ is the mass of single electrode. ${ }^{34}$ All of the measurements were carried out at room temperature, $25^{\circ} \mathrm{C}$.

\section{Results and Discussion}

\subsection{Physical properties}

Figure 1 compares the XRD spectra of the SS0, SS1 and SS2. The SS used in the present study has a crystalline structure, as evidenced by the presence of typical sharp diffraction peaks $\left(\begin{array}{lll}1 & 1 & 0\end{array}\right)$ and $\left(\begin{array}{ll}2 & 20\end{array}\right)$ at $2 \theta=43.55^{\circ}$ and $50.72^{\circ}$, respectively, in its XRD spectra for the SS crystalline material..$^{35}$ The intensity and shape of these peaks remain same with etching, indicating that the etching did not change the structure of the SS. A relatively broad diffraction peak $\left(\begin{array}{lll}1 & 1 & 1\end{array}\right)$ found at $2 \theta=38.65^{\circ}$ on the SS1 and SS2 XRD spectra indicates the presence of PtNs on the SS surface and the peak broadening indicates that the PtNs is in semi-crystalline form. ${ }^{36}$

Figures 2(a), (b), (c) and (d) respectively show the FESEM images of the bare SS surface, the etched SS surface, bare SS surface deposited with PtNs and the etched SS surface deposited with PtNs. It can be observed that the SS surface becomes very rough after etching by an acid treatment [Figs. 2(a) and (b)]. The presence of PtNs on the respective current collectors indicates that the deposition occurred successfully and the PtNs are distributed uniformly throughout the surface of the SS, with the particle sizes ranging approximately from $\sim 30 \mathrm{~nm}$ to $\sim 70 \mathrm{~nm}$ [Figs. 2(c) and (d)]. 


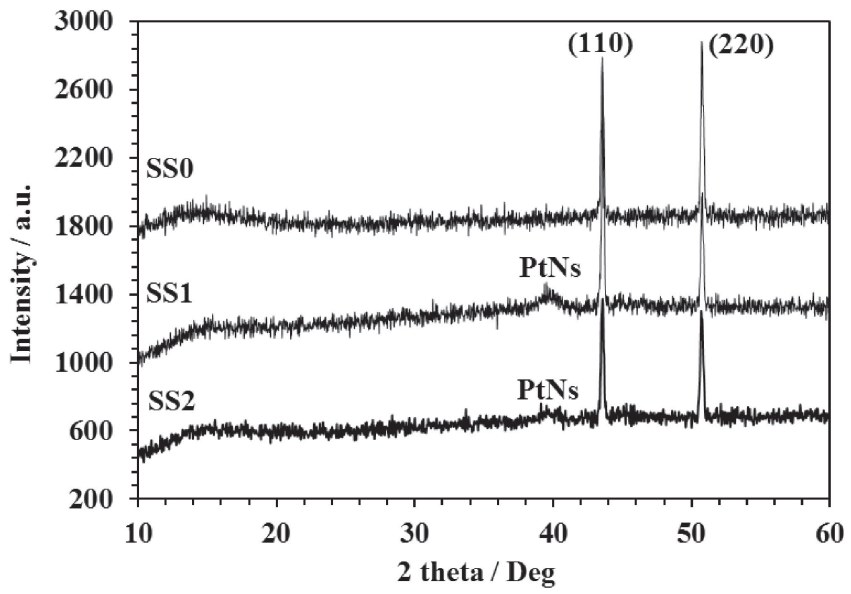

Figure 1. X-ray diffraction patterns for the current collectors: SS0, SS1 and SS2.

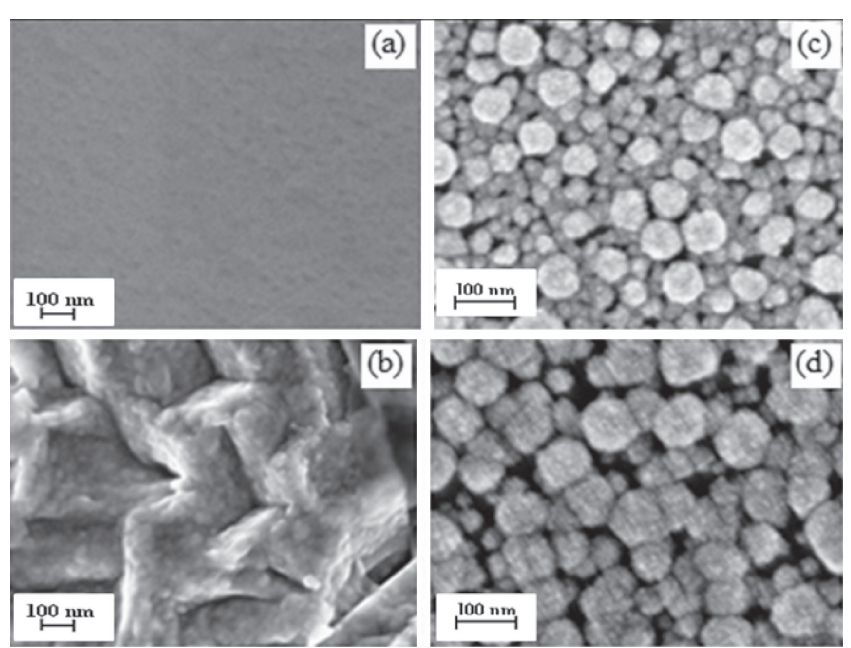

Figure 2. FESEM micrographs for SS0 (a), SS0 after etched (b), SS1 (c), and SS2 (d).

Further, it can be seen that PtNs particles on the etched surface appear to have slightly bigger particle size which may be resulted from the effect that the rough surface can promote the growth of particles leading to the bigger particle size.

Figures $3(\mathrm{a}, \mathrm{b}, \mathrm{c})$ shows the comparison of EDAX results for the SS0, SS1 and SS2. The peaks corresponding to the elements in SS only are clearly observed in Fig. 3(a). The EDAX peaks corresponding to PtNs particles are observed on the SS1 and SS2 surfaces which are as shown in Figs. 3(b) and (c), respectively. According to the values in the tables attached to Figs. 3(b) and (c), it can be seen that the weight percentage of the Pt element attached on etched SS surface is higher than that on the un-etched SS surface. This result infers that more efficient deposition may take place on the rough surface than on the smooth surface of the SS.

The XPS spectra for the sample SS0 (not shown here) indicates the presence of typical peaks for stainless steel material, with their detail as shown in Table $1 .{ }^{37,38}$ Similarly for the XPS spectra of the samples SS1 and SS2 (not shown here), there are typical peaks for the platinum material, which are found at the binding energies as shown in Table $1 .{ }^{39,40}$

Table 1 clearly shows that oxygen and carbon are found on the surfaces of all the samples but, as expected, each sample has different level of mass concentration of these elements because their surfaces have different chemical states characteristics. The results in this table also show that the Pt mass concentration is slightly higher $(\sim 3 \%)$ for the Pt deposition made on the SS etched surface,
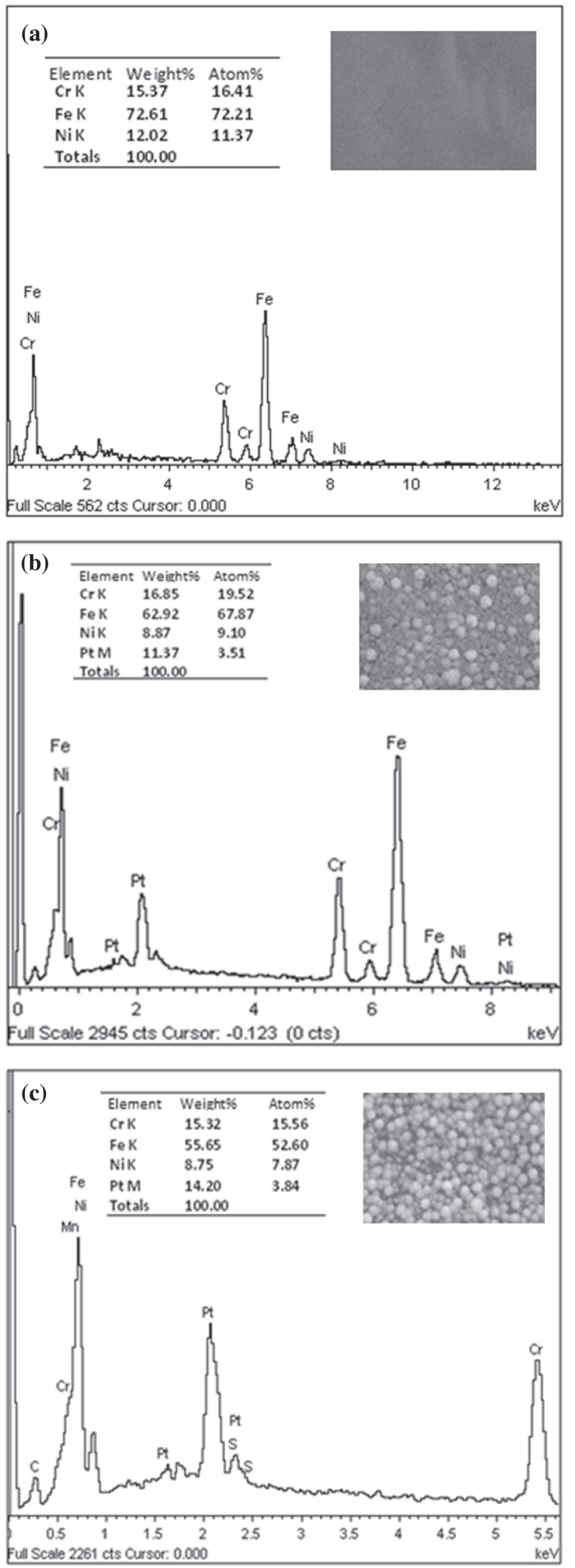

Figure 3. EDAX results for SS0 (a), SS1 (b), and SS2 (c).

indicating that surface roughness (on SS2) can help promoting higher growth of deposited Pt. This result is in agreement with the EDAX results, which also indicates that the surface roughness can allow a more efficient deposition of $\mathrm{Pt}$ with a higher mass concentration.

The $\mathrm{N}_{2}$ adsorption-desorption isotherm data for the ACMs electrodes used for fabricating supercapacitor cells is shown in Fig. 4. According to the International Union of Pure and Applied 
Table 1. Elemental peaks position determined from the XPS spectra for the samples SS0, SS1, and SS2.

\begin{tabular}{ccccc}
\hline Samples & Peaks & $\begin{array}{c}\text { Binding energy } \\
(\mathrm{eV})\end{array}$ & $\begin{array}{c}\text { Atomic conc. } \\
(\%)\end{array}$ & $\begin{array}{c}\text { Mass conc. } \\
(\%)\end{array}$ \\
\hline \multirow{6}{*}{ SS0 } & O 1s & 530 & 39.65 & 25.59 \\
& C 1s & 285 & 34.58 & 16.76 \\
& Cr 2p & 576 & 2.19 & 4.60 \\
& Fe 2p & 711 & 21.66 & 48.41 \\
& Mn 2p & 642 & 1.91 & 4.24 \\
\hline \multirow{3}{*}{ SS1 } & O 1s & 531 & 16.59 & 4.43 \\
& C 1s & 285 & 57.62 & 11.56 \\
& Pt 4f & 75 & 25.79 & 84.01 \\
\hline \multirow{4}{*}{ SS2 } & O 1s & 531 & 17.35 & 3.90 \\
& C 1s & 285 & 50.72 & 8.56 \\
& Pt 4f & 72 & 31.93 & 87.54 \\
\hline
\end{tabular}

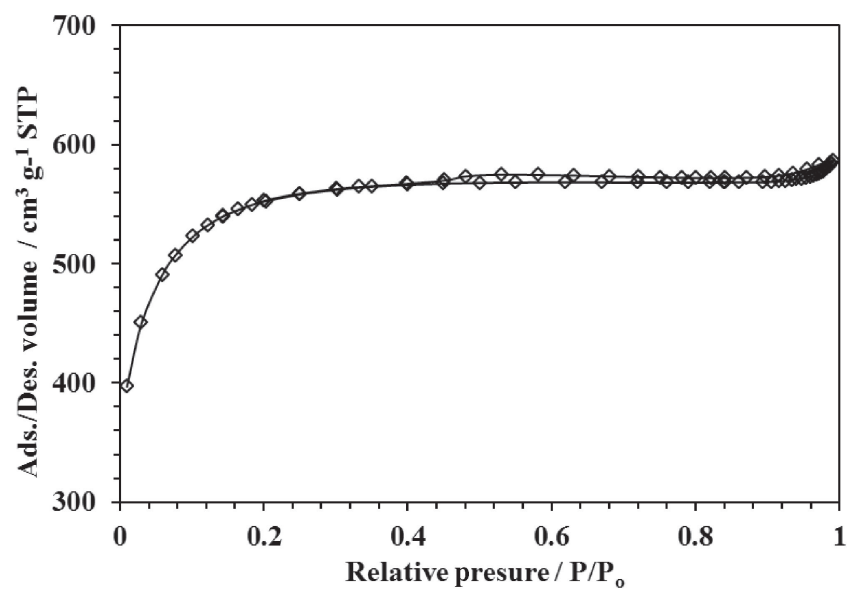

Figure 4. Nitrogen adsorption-desorption isotherm for ACM electrode.

Table 2. The porosity data of the ACM electrodes prepared from pre-carbonized OPEFB.

\begin{tabular}{cccccc}
\hline $\begin{array}{c}S_{\text {BET }} \\
\left(\mathrm{m}^{2} \mathrm{~g}^{-1}\right)\end{array}$ & $\begin{array}{c}S_{\text {Meso }} \\
\left(\mathrm{m}^{2} \mathrm{~g}^{-1}\right)\end{array}$ & $\begin{array}{c}S_{\text {Micro }} \\
\left(\mathrm{m}^{2} \mathrm{~g}^{-1}\right)\end{array}$ & $\begin{array}{c}V_{\text {Meso }} \\
\left(\mathrm{cm}^{3} \mathrm{~g}^{-1}\right)\end{array}$ & $\begin{array}{c}V_{\text {Micro }} \\
\left(\mathrm{cm}^{3} \mathrm{~g}^{-1}\right)\end{array}$ & $\begin{array}{c}D \\
(\mathrm{~nm})\end{array}$ \\
\hline 1704 & 539 & 1165 & 0.273 & 0.616 & 21.603 \\
\hline
\end{tabular}

Chemistry (IUPAC) classification scheme, this isotherm belongs to the type-IV profile. ${ }^{41}$ The isotherm curve behaviour with a sudden increase in the adsorbed volume and a rounded knee of the curve in the lower range of relative pressure indicates that the samples possess a wide pore size distribution that ranges from micropores to mesopores.

Furthermore, the isotherms data in relatively higher pressure range $\left(P / P_{\mathrm{o}}>0.1\right)$ show a linear change in the adsorption capacity with increasing pressure, suggesting the existence of a much more widely distributed and heterogeneous microporosity. The BET surface area $\left(S_{\mathrm{BET}}\right)$, mesopore area $\left(S_{\text {Meso }}\right)$, micropore area $\left(S_{\text {Micro }}\right)$, mesopore volume $\left(V_{\text {Meso }}\right)$, micropore volume $\left(V_{\text {Micro }}\right)$, and average pore diameter $(D)$ calculated from the isotherms data are listed in Table 2. These data show that the ACM electrodes have a high surface area which has predominantly resulted from more than $60 \%$ micropores. Figure 5 shows the size distribution of pores, with the average pore diameter larger than $20 \mathrm{~nm}$, representing an overall pore characteristic of the electrodes.

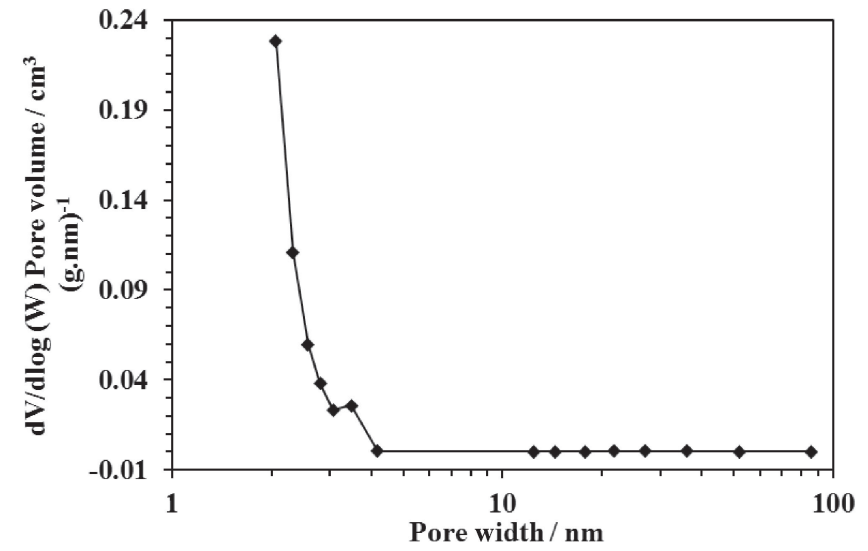

Figure 5. Pore volume versus pore width for ACM electrode.
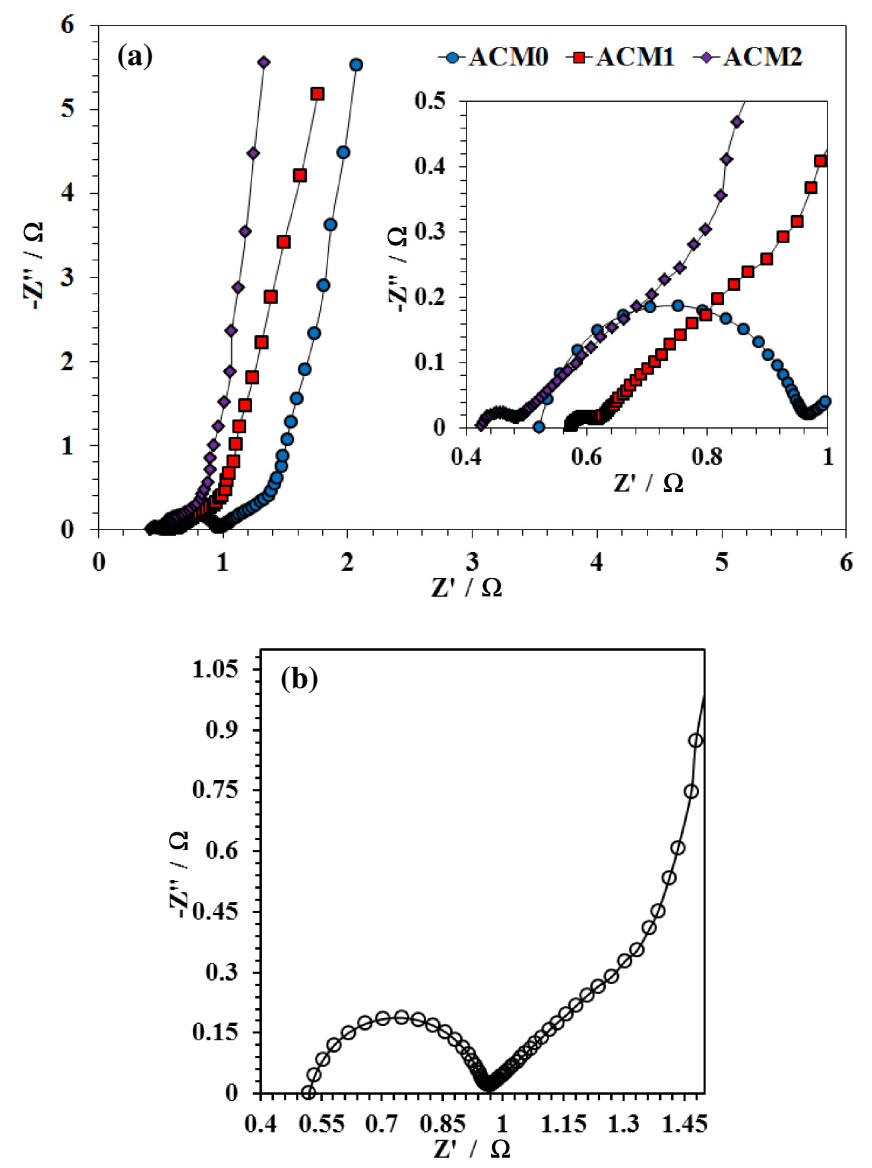

Figure 6. (Color online) Nyquist plots for ACM0, ACM1 and ACM2 cells (a), expanded Niquist plot showing Warburg region for ACM0 (b).

\subsection{Electrochemical properties}

The Nyquist plots (i.e., complex impedance plots) of the EIS data for ACM0, ACM1 and ACM2 cells are shown in Fig. 6. For all the cells, the curves consist of a semicircle with an intercept on the real $\left(Z^{\prime}\right)$ axis at $R_{\mathrm{s}}$ for the high-frequency region and at $R_{\mathrm{p}}$ for the lower frequency region, where $R_{\mathrm{S}}$ is the resistance across the electrolyte and interface between the current collectors and the electrodes, and $R_{\mathrm{p}}$ is the internal resistance of the electrodes. It can be observed from the inset of Fig. 6(a) that for the deposition on un-etched SS surface the reduction in the $R_{\mathrm{S}}$ value is negligibly small, however, with etching the value of $R_{\mathrm{S}}$ reduced by $18 \%$ (i.e. from $0.5 \Omega$ to $0.4 \Omega$ ). This reduced value of $R_{\mathrm{S}}$ is resulted from a significant improvement in the contact between the etched SS surface 
Table 3. The values of $R_{\mathrm{s}}, R_{\mathrm{p}}$, ESR, and $C_{\mathrm{sp}}$ from EIS data.

\begin{tabular}{ccccc}
\hline Cells & $\begin{array}{c}R_{\mathrm{s}} \\
(\Omega)\end{array}$ & $\begin{array}{c}R_{\mathrm{p}} \\
(\Omega)\end{array}$ & $\begin{array}{c}\mathrm{ESR} \\
(\Omega)\end{array}$ & $\begin{array}{c}C_{\mathrm{sp}} \\
\left(\mathrm{F} \mathrm{g}^{-1}\right)\end{array}$ \\
\hline ACM0 & 0.519 & 0.957 & 1.332 & 105 \\
ACM1 & 0.571 & 0.615 & 0.897 & 112 \\
ACM2 & 0.424 & 0.482 & 0.710 & 115 \\
\hline
\end{tabular}

Table 4. Specific capacitance values estimated from EIS $(10 \mathrm{mHz}), \mathrm{CV}\left(1 \mathrm{mV} \mathrm{s}^{-1}\right)$ and $\mathrm{GCD}\left(10 \mathrm{~mA} \mathrm{~cm}^{-2}\right)$ techniques for ACM0, ACM1 and ACM cells.

\begin{tabular}{cccc}
\hline Cells & $\begin{array}{c}\text { EIS } \\
\left(\mathrm{F} \mathrm{g}^{-1}\right)\end{array}$ & $\begin{array}{c}\mathrm{CV} \\
\left(\mathrm{Fg} \mathrm{g}^{-1}\right)\end{array}$ & $\begin{array}{c}\mathrm{GCD} \\
\left(\mathrm{Fg}^{-1}\right)\end{array}$ \\
\hline ACM0 & 105 & 141 & 142 \\
ACM1 & 112 & 145 & 150 \\
ACM2 & 115 & 146 & 150 \\
\hline
\end{tabular}

containing PtNs and the surface of the carbon electrodes, which may lead to an efficient electronic charges transferred from the SS2 current collector to the carbon electrode. Further, the data in Fig. 6(a), (inset) also show a decrease in $R_{\mathrm{p}}$ (the intercept of the semicircle on the real axis at lower frequency) by almost $32 \%$ (i.e. from $0.9 \Omega$ to $0.6 \Omega$ ) and $50 \%$ (from $0.9 \Omega$ to $0.5 \Omega$ ) due to the presence of the PtNs on the SS1 and SS2, respectively. The influencing factors to this change are normally associated with the change in the porous structure of the electrode..$^{42}$ However, since all the cells used the same electrodes then the possible reason for such $R_{\mathrm{p}}$ value reduction must be externally driven, i.e. the improvement in the ability of ionic charges to diffuse into pores of electrodes which is in contact with the SS2. The driving factor for this improvement could be the presence of deposited PtNs on the etched SS2, which allow efficient mobility of electronic charges into electrodes needed for forming an electric double layer of electronicionic charges at the electrode-electrolyte interface.

It is well known that the resistance, $R_{\mathrm{p}}-R_{\mathrm{S}}$ depends on the pore characteristic of the electrode material and the ionic accessibility into the pores of electrodes. The $R_{\mathrm{p}}-R_{\mathrm{S}}$ values of ACM1 and ACM2 cells determined from Fig. 6(a) (or Table 3) are significantly lower than that of ACM0 cell, which indicate that both the cells with PtNs have better ionic and electronic conductivity. Figure 6(a), can also be interpreted in terms of $\mathrm{ESR}^{10,43}$ which determines the power capability of the supercapacitors. The ESR values for the ACM0, ACM1 and ACM2 cells are found to be $1.33 \Omega, 0.90 \Omega$, and $0.71 \Omega$, respectively. Further, it can also be determined from EIS data that the ACM2 cell has the shortest length of the Warburg diffusion impedance line [Fig. 6(b)]. These features are the attributes to the ion migration efficiency through the carbon electrode, which seem to be enhanced by the PtNs deposited on the etched surface of the current collector. ${ }^{44}$ Therefore, these results demonstrate that the ACM1 and ACM2 cells exhibit the better performance than the ACM0 cell. Possibly, this change dominantly occurred at the region near the carbon surface only because some of the PtNs may penetrate into some pores in the region near the surface of the electrode. A difference in the specific capacitance of the cells, observed in Table 4, may arise from the presence of PtNs on the current collector, which changes the rate of charges (ionic and electronic) transfer to accumulate charges on the pore walls of the electrodes or the capacity of electrolyte ions to diffuse into the pores of the carbon electrode.

Figure 7 shows the variation in the real $\mathrm{C}^{\prime}$ and imaginary $\mathrm{C}^{\prime \prime}$ parts of the capacitance values with frequency for the ACM0,

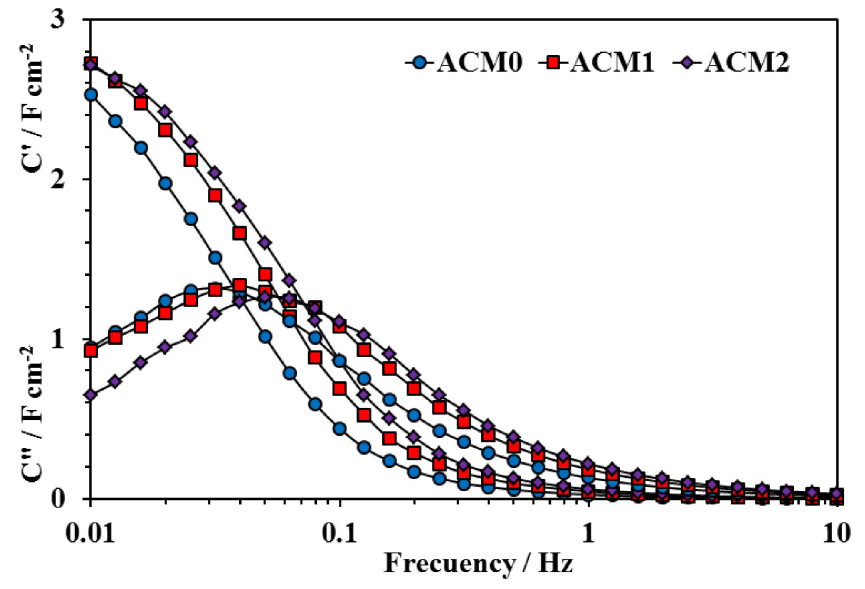

Figure 7. (Color online) Variation of the real and imaginary parts of the capacitance with frequency plotted from EIS data for ACM0, ACM1 and ACM2 cells.

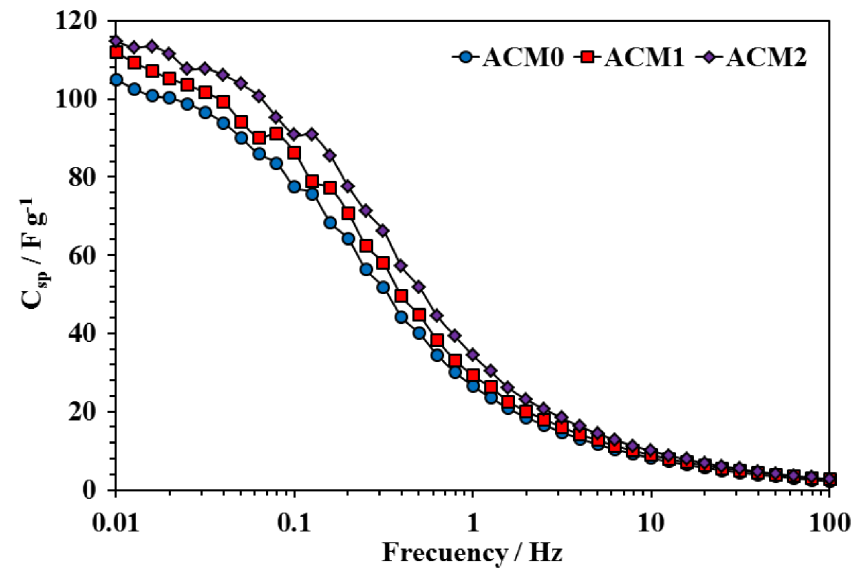

Figure 8. (Color online) Capacitance as a function of frequency plotted from EIS data for ACM0, ACM1 and ACM2 cells.

ACM1 and ACM2 cells. The role of the PtNs in increasing the value of $\mathrm{C}^{\prime}$ and $\mathrm{C}^{\prime \prime}$ across the entire low-frequency region is clearly shown and the etching seems to enhance such an increasing effect. It can be seen that the PtNs change the peak position of the $C^{\prime \prime}$ curve $\left(f_{p}\right)$, which is inversely proportional to the relaxation time,

$$
\tau_{o}=1 / f_{p}
$$

It has been reported that shorter relaxation time yields better power delivery. ${ }^{45,46}$ In our study, the PtNs seems to improve the power delivery due to the fact that the peaks for the ACM1 and ACM2 cells give a shorter relaxation time $\left(\tau_{o}=25 \mathrm{~s}\right.$ and $16 \mathrm{~s}$, respectively), compared with that of ACM0 cell $\left(\tau_{o}=32 \mathrm{~s}\right)$. Here, the etching seems to further reduce the value of $\tau_{o}$, which is needed for an efficient power delivery.

Figure 8 shows the variation in the specific capacitance of ACM0, ACM1 and ACM2 cells as a function of frequency. The specific capacitance of the cells was evaluated at $10 \mathrm{mHz}$ from the Niquist plot using equation:

$$
C_{\mathrm{sp}}=-2 /\left(2 \pi f Z^{\prime \prime} m\right)
$$

where, $f$ is the frequency, $Z^{\prime \prime}$ is the imaginary part of the impedance and $m$ is the mass of the single electrode. ${ }^{47}$

It was observed that PtNs deposition on SS improved the specific capacitance of a cell, particularly in the low-frequency region (below $10 \mathrm{~Hz}$ ). In the high-frequency region (above $10 \mathrm{~Hz}$ ), a small effect due to PtNs is observed. These results demonstrate a 

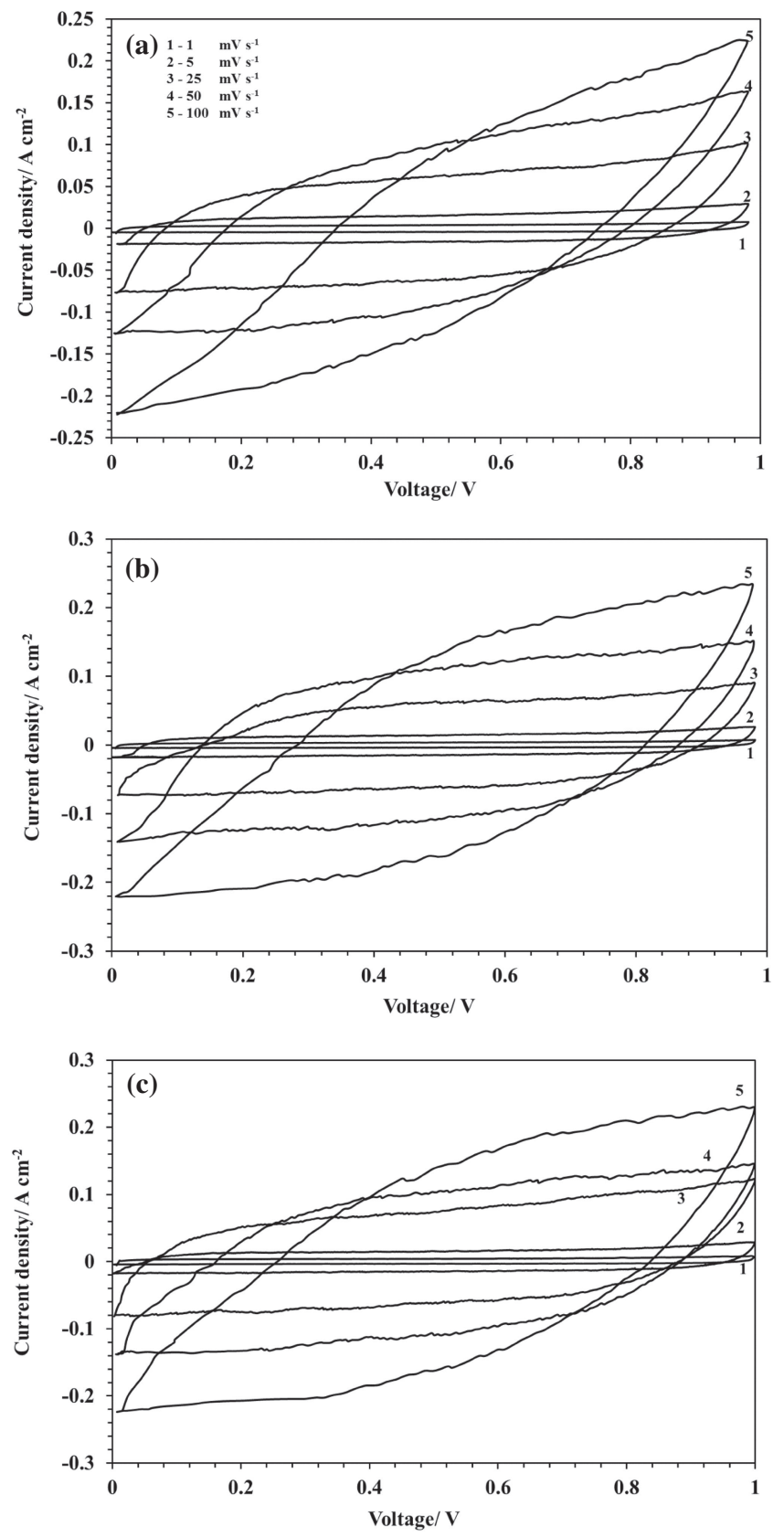

Figure 9. Cyclic voltamograms of ACM0 (a), ACM1 (b), and ACM2 (c) cells.

significant effect of etching applied on SS surface, when the gain of $C_{\text {sp }}$ for ACM2 cell over ACM0 is almost double than that for ACM1 over ACM0, particularly in the lower frequency region (below $1 \mathrm{~Hz})$.

Figures 9(a), (b) and (c) compare the CV results for ACM0, $\mathrm{ACM} 1$ and ACM2 cells measured from $0.1 \mathrm{~V}$ to $1.0 \mathrm{~V}$ over a range of scan rate from 1 to $100 \mathrm{mV} \mathrm{s}^{-1}$. It can be observed that the ACM1 and ACM2 cells exhibit nearly an ideal EDLC behaviour with rectangular $\mathrm{CV}$ curves and larger voltammetric current even at higher scan rate $\left(50 \mathrm{mV} \mathrm{s}^{-1}\right)$ as compared to the ACM0 cell which maintains near rectangular shape up to a lower scan rate of $25 \mathrm{mV} \mathrm{s}^{-1}$. Further, the ACM1 and ACM2 cells show less deviation from rectangular shape beyond $50 \mathrm{mV} \mathrm{s}^{-1}$ as opposed to the ACM0 cell for which the $\mathrm{CV}$ profiles start deviating from the ideal behaviour (i.e. become narrower and more oblique) even at lower value of scan rate $\left(25 \mathrm{mV} \mathrm{s}^{-1}\right)$. This demonstrates that the electrodes ACM1 and ACM2 offer smaller equivalent series resistance (ESR) and better rate capabilities that give rise to rapid charging/

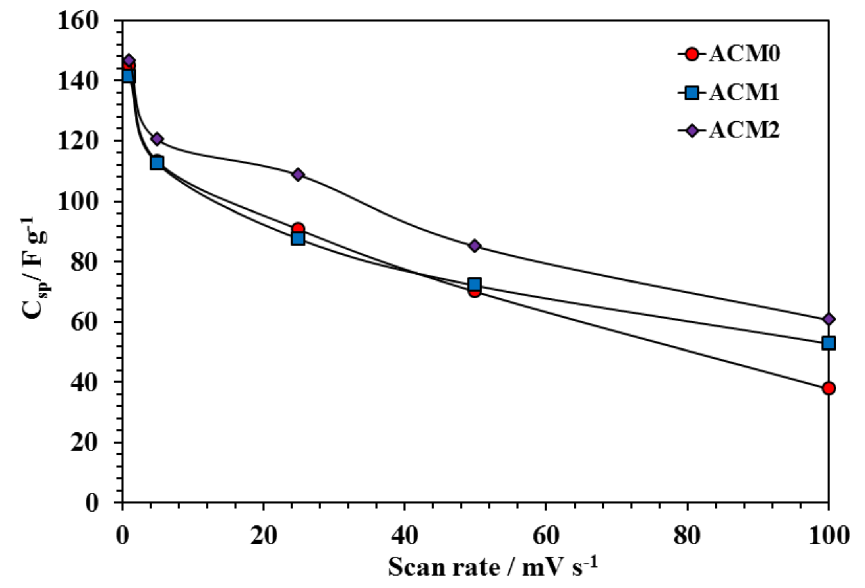

Figure 10. (Color online) Specific capacitance versus scan rate $\left(\mathrm{mV} \mathrm{s}^{-1}\right)$ for ACM0, ACM1 and ACM2 cells.

discharging operation as compared to the ACM0 cell. Another notable feature of the $\mathrm{CV}$ curves is that no humps for redox currents (implying absence of pseudo-capacitive effects) in the positive or negative sweeps over the selected potential range have been observed. This characteristic is typical for supercapacitors that use carbon based materials as electrodes. Similar kind of variation in the CV patterns with increasing scan rate have also been discussed elsewhere. ${ }^{48-50}$

The specific capacitance values of the cells were calculated at a scan rate of $1 \mathrm{mV} \mathrm{s}^{-1}$ from the $\mathrm{CV}$ curves in Fig. 9 using equation:

$$
C_{\mathrm{sp}}=2 I /(\mathrm{sm})
$$

where, $I$ is the current, $s$ is the scan rate and $m$ is the mass of the single electrode. ${ }^{51}$ The calculated values of the specific capacitance are given in Table 4. These results are in a similar trend with those obtained by the other two methods, EIS and GCD. The deposition of PtNs on SS and etched SS current collectors improves the specific capacitance of the cells. A more clear improvement in terms of specific capacitance retention/fading with increasing scan rate can be seem in Fig. 10, where $C_{\mathrm{sp}}$ for ACM2 cell for all scan rate values shows the least fading compared to other cells. These results indicate a significant effect of etching applied on the SS surface. Further, the overall fading in specific capacitance observed for all the cells over the entire voltage scan rate can be explained as follows:

(i) At higher scan rates relatively high current is delivered by the EDLC cell that results in a more considerable voltage loss $(\Delta \mathrm{V})$. This voltage loss, being resistive in nature, is a parasitic process that subtracts part of the capacitance of the device particularly at higher current flows. ${ }^{52}$

(ii) The electric charges find it difficult to occupy homogeneously and rapidly all the available sites at the electrode/electrolyte interface due to their limited rate of orientation and migration in the electrolyte (low local ionic conductivity) adsorbed in the narrow pores (torturous and bottle-neck micropores) of electrodes that are farther from the bulk of the electrolyte. ${ }^{52,53}$

Figure 11 shows a comparison of the GCD charge-discharge behaviour of ACM0, ACM1 and ACM2 cells over the potential range of $0-1 \mathrm{~V}$ at current densities of 10 and $30 \mathrm{~mA} \mathrm{~cm}^{-2}$. All the charge and discharge curves exhibit almost linear behaviour. There is a sharp drop in the voltage which appears at the beginning of the discharge curve, which is associated with the ESR of the supercapacitor cells. The ESR values of the ACM0, ACM1 and ACM2 cells, calculated from this sharp voltage drop are found to be $1.75 \Omega, 1.487 \Omega$ and $0.974 \Omega$, respectively, again confirming the effect of etching on the ESR values of the cells. The specific capacitance of the cells was calculated at a current density of $10 \mathrm{~mA} \mathrm{~cm}^{-2}$ from the discharge curve using the equation: 


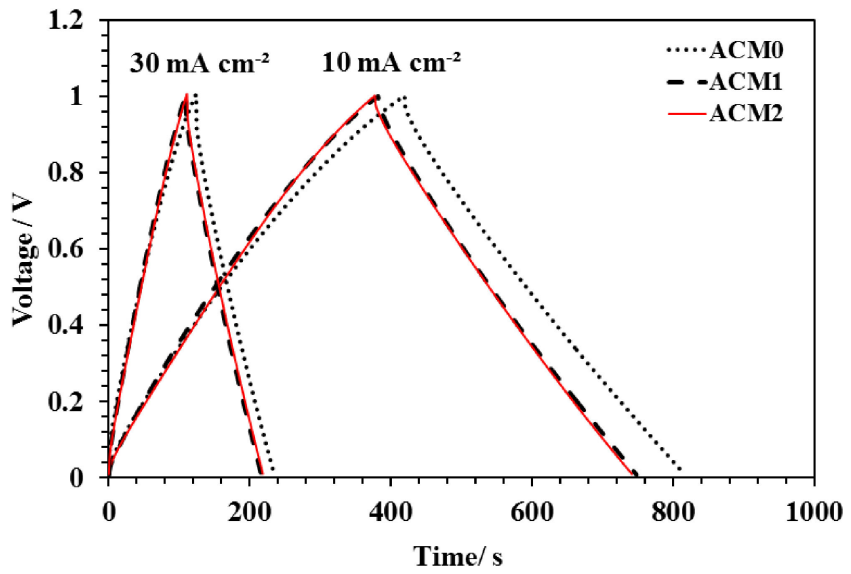

Figure 11. (Color online) GCD curves for ACM0, ACM1 and ACM2 cells, measured at current densities of 10 , and $30 \mathrm{~mA} \mathrm{~cm}^{-2}$.

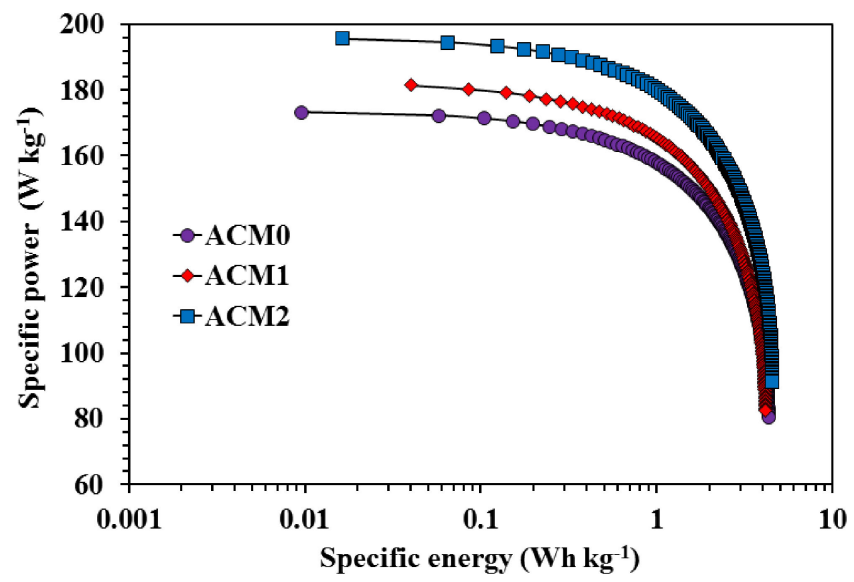

Figure 12. (Color online) Ragone plots for ACM0, ACM1 and ACM2 cells.

$$
C_{\mathrm{sp}}=2 I \Delta t /(m \Delta V)
$$

where, $I$ is the discharge current, $\Delta t$ is the discharge time, $\Delta V$ is the voltage and $m$ is the mass of the active material (electrode) ${ }^{54}$ The calculated values of the specific capacitance are listed in Table 4 and exhibit the same trend as those obtained from the CV and EIS methods, which once again shows the evidence of beneficial effect from etching applied on the SS surface. The values of the specific power $(P)$ and specific energy $(E)$ were calculated from the chargedischarge curves (Fig. 11) using Eqs. (7) and (8) respectively,

$$
\begin{aligned}
& P=V i / m \\
& E=V i t / m
\end{aligned}
$$

where: $i$ is the discharge current, $V$ is the voltage excluding the $i R$ drop occurring at the beginning of the discharge, $t$ is time in $\mathrm{h}$ and $m$ is the mass. ${ }^{55}$

Figure 12 shows Ragone plots that compare the variation of the specific power with the specific energy of ACM0, ACM1 and ACM2 cells. All the cells exhibit a typical specific power-specific energy relationship and possess a very similar shape, with a specific energy that remains almost unchanged at low specific power and then gradually decreasing before showing a relatively larger decrease in the region of higher specific power. Despite having a very similar shape, the differences in their values clearly reveal the role of PtNs deposited on etched SS in producing an improved specific power-specific energy relationship, as shown in Table 4, with the improved values.

\section{Conclusion}

Based on the electrochemical data analysis using the EIS, CV and GCD methods, SS current collectors whose surfaces were modified by etching and then deposited with PtNs were found to provide a better contact with the supercapacitor monolithic carbon electrodes prepared from pre-carbonized fibres of OPEFB, thereby exhibiting an improved supercapacitive performance with respect to the supercapacitor cells using bare stainless steel current collectors or un-etched current collector deposited with PtNs. It is clearly demonstrated that the etching of the surface of SS current collector prior to the PtNs deposition has played a significant role to achieve a maximum increase of $10 \%$ in specific capacitance, and hence $9 \%$ in specific energy. Also a maximum decrease of $47 \%$ in ESR value has been detected that results in an increase of $13 \%$ in specific power.

\section{Acknowledgments}

We acknowledge the grants from the Ministry of Higher Education (FRGS/2/2013/ST05/UKM/01/1), Ministry of Science, Technology and Innovation (MOSTI) (03-01-02-SF1118) and Universiti Kebangsaan Malaysia (DIP-2014-027, UKM-Industri2013-023) and the support of CRIM (Centre for Research and Innovation Management), UKM. The authors also thank to Mr. Saini for help with the laboratory work and for the collaborative work of Department of Physics and Astrophysics, University of Delhi, India.

\section{References}

1. R. Kötz and M. Carlen, Electrochim. Acta, 45, 2483 (2000).

2. A. Burke, J. Power Sources, 91,37 (2000).

3. P. Simon and Y. Gogotsi, Nat. Mater., 7, 845 (2008).

4. B. E. Conway, Electrochemical Supercapacitors: Scientific Fundamentals and Technological Applications, Kluwer Academic/Plenum, New York, (1999).

5. P. Ratajczak, K. Jurewicz, and F. Beguin, J. Appl. Electrochem., 44, 475 (2014).

6. N. S. M. Nor, M. Deraman, R. Omar, R. Farma, N. H. Basri, B. N. M. Dolah, N. F. Mamat, B. Yatim, and M. Norizam, Energy, 79, 183 (2015).

7. Y. Gong, Z. Wei, J. Wang, P. Zhang, and Y. W. H. Li, Sci. Rep., 4, 6349 (2014).

8. S. Wang, R. Liu, C. Han, J. Wang, M. Li, J. Yao, H. Li, and Y. Wang, Nanoscale, 6, 13510 (2014)

9. P. L. Taberna, C. Portet, and P. Simon, Appl. Phys. A: Mater. Sci. Process., 82, 639 (2006).

10. A. G. Pandolfo and A. F. Hollenkamp, J. Power Sources, 157, 11 (2006).

11. C. Portet, P. L. Taberna, P. Simon, and C. Laberty-Robert, Electrochim. Acta, 49, 905 (2004).

12. R. Farma, M. Deraman, I. A. Talib, Awitdrus, R. Omar, M. M. Ishak, E. Taer, N. H. Basri, and B. N. M. Dolah, AIP Conf. Proc., 1656, 030006 (2015).

13. M. Suleman, Y. Kumar, and S. A. Hashmi, J. Phys. Chem. B, 117, 7436 (2013).

14. H. C. Wu, Y. P. Lin, E. Lee, W. T. Lin, J. K. Hu, H. C. Chen, and N. L. Wu, Mater. Chem. Phys., 117, 294 (2009).

15. Y. Show and K. Imaizumi, Diam. Relat. Mater, 16(4-7), 1154 (2007).

16. A. Kumar, G. Hegde, S. A. B. A. Manaf, Z. Ngaini, and K. V. Sharma, Chem. Commun., 50(84), 12708 (2014).

17. G. A. M. Ali, S. A. B. Manaf, A. Kumar, K. F. Chong, and G. Hegde, J. Phys. D: Appl. Phys., 47, 495307 (2014).

18. V. Ruiz, C. Blanco, R. Santamaría, J. M. Ramos-Fernández, M. MartínezEscandell, A. Sepúlveda-Escribano, and F. Rodríguez-Reinoso, Carbon, 47, 195 (2009).

19. A. Garcia-Gomez, P. Miles, T. A. Centeno, and J. M. Rojo, Electrochim. Acta, 55, 8539 (2010).

20. E. Taer, M. Deraman, I. A. Talib, A. A. Umar, M. Oyama, and R. M. Yunus, Curr. Appl. Phys., 10, 1071 (2010).

21. N. H. Basri, M. Deraman, S. Kanwal, I. A. Talib, J. G. Manjunatha, A. A. Aziz, and R. Farma, Biomass Bioenergy, 59, 370 (2013).

22. R. Farma, M. Deraman, A. Awitdrus, I. A. Talib, E. Taer, and N. H. Basri, Bioresour. Technol., 132, 254 (2013).

23. B. N. M. Dolah, M. Deraman, M. A. R. Othman, R. Farma, E. Taer, N. H. Basri, I. A. Talib, R. Omar, and N. S. M. Nor, Mater. Res. Bull., 60, 10 (2014).

24. E. Taer, M. Deraman, I. A. Talib, A. Awitdrus, S. A. Hashmi, and A. A. Umar, Int. J. Electrochem. Sci., 6, 3301 (2011).

25. A. Awitdrus, M. Deraman, I. A. Talib, R. Farma, R. Omar, M. M. Ishak, N. H. Basri, and B. N. M. Dolah, Adv. Mater. Res., 501, 13 (2012).

26. R. Farma, M. Deraman, I. A. Talib, R. Omar, J. G. Manjunatha, and M. M. Ishak, 
Int. J. Electrochem. Sci., 8, 257 (2013).

27. N. S. M. Nor, M. Deraman, R. Omar, E. Taer, R. Farma, N. H. Basri, and B. N. M. Dolah, AIP Conf. Proc., 1586, 68 (2014)

28. E. Taer, Sugianto, M. A. Sumantre, R. Taslim, and M. Deraman, Adv. Mater. Res., 896, 66 (2014)

29. E. Taer, M. Deraman, I. A. Talib, S. A. Hashmi, and A. A. Umar, Electrochim. Acta, 56, 10217 (2011)

30. M. Deraman, J. Phys. D: Appl. Phys., 27, 1060 (1994)

31. M. Deraman, S. Zakaria, R. Omar, and A. A. Aziz, Jpn. J. Appl. Phys., 39, 1236 (2000).

32. M. Deraman, M. P. Ismail, and M. M. D. Said, J. Mater. Sci. Lett., 14, 781 (1995)

33. G. Chang, M. Oyama, and K. Hirao, Thin Solid Films, 515, 3311 (2007).

34. C. Emmenegger, P. Maouron, P. Sudan, P. Wenger, V. Hermann, R. Gallay, and A. Zuttel, J. Power Sources, 123, 321 (2003).

35. A. Szymanska, D. Oleszak, A. Grabia, M. Rosinski, K. Sikorski, J. Kazior, A. Michalski, and K. J. Kurzydlowski, Adv. Mater. Sci., 8, 143 (2004).

36. Z. Peng and H. Yang, Nano Today, 4, 143 (2009).

37. M. Cavallini, Mater. Chem., 5, 29 (1980).

38. P. Stefanov, D. Stoychev, M. Stoycheva, A. R. Gonzalez-Elipe, and T. Marinova, Surf. Interface Anal., 28, 106 (1999).

39. Z. Ibrahim, Z. Othaman, M. M. A. Karim, and D. Holland, Solid State Sci. Technol., 15, 65 (2007).

40. C. Dablemont, P. Lang, C. Mangeney, J.-Y. Piquemal, V. Petkov, F. Herbst, and
G. Viau, Langmuir, 24, 5832 (2008).

41. K. S. W. Sing, D. H. Everett, R. A. W. Haul, L. Moscou, R. A. Pierotti, J. Rouquerol, and T. Siemieniewska, Pure Appl. Chem., 57, 603 (1985).

42. J. Gamby, P. L. Taberna, P. Simon, J. F. Fauvarque, and M. Chesneau, J. Power Sources, 101, 109 (2001).

43. L. L. Zhang and X. S. Zhao, Chem. Soc. Rev., 38, 2520 (2009).

44. C.-W. Huang, C.-H. Hsu, P.-L. Kuo, C.-T. Hsieh, and H. Teng, Carbon, 49, 895 (2011).

45. C. Portet, P. L. Taberna, P. Simon, E. Flahaut, and C. Laberty-Robert, Electrochim. Acta, 50, 4174 (2005).

46. D. Pech, M. Brunet, H. Duron, P. Huang, V. Mochalin, Y. Gogotsi, P.-L. Taberna, and P. Simon, Nat. Nanotechnol., 162, 651 (2010).

47. Y. Zhu, H. Hu, W. Li, and X. Zhang, Carbon, 45, 160 (2007).

48. L. Zhang and G. Shi, J. Phys. Chem. C, 115, 17206 (2011).

49. L. Jiang, J. Yan, L. Hao, R. Xue, G. Sun, and B. Yi, Carbon, 56, 146 (2013).

50. M. Suleman, Y. Kumar, and S. A. Hashmi, J. Solid State Electrochem., 19, 1347 (2015).

51. X. Li, C. Han, X. Chen, and C. Shi, Micropor. Mesopor. Mat., 131, 303 (2010).

52. P. Staiti and F. Lufrano, J. Electrochem. Soc., 152, A617 (2005).

53. A. Kajdos, A. Kvit, F. Jones, J. Jagiello, and G. Yushin, J. Am. Chem. Soc., 132, 3252 (2010).

54. H. Wang, Q. Gao, and J. Hu, Micropor. Mesopor. Mat., 131, 89 (2010).

55. S. R. S. Prabaharan, R. Vimala, and Z. Zainal, J. Power Sources, 161, 730 (2006). 